\title{
Modelling of the Auditory Satisfaction Function for the Automobile Door Opening Quality
}

\author{
Wonjoon Kim ${ }^{1}$, Taebeum Ryu ${ }^{2}$, Yushin Lee ${ }^{1}$, Donggun Park ${ }^{1}$, Myung Hwan Yun ${ }^{1}$ \\ ${ }^{1}$ Department of Industrial Engineering, Seoul National University, Seoul, 151-742 \\ ${ }^{2}$ Department of Industrial and Management Engineering, Hanbat National University, Daejeon, 305-719
}

\begin{abstract}
This study aims to determine the affective response that occurs when the driver listens to door opening sound of vehicles by analyzing the relationship of sound parameters and the affective satisfaction. For the purpose of this study, we conducted an experiment with 26 vehicles and 30 subjects. The subjects evaluated the door opening sounds of the vehicles on affective satisfaction by answering a standard affective evaluation. Through multiple regression analysis, the result of evaluation was utilized to create a model that can presume the satisfaction of door opening sound. As the result of the regression analysis, 'SharpnessZ', 'Short-term loudness', and 'Roughness' turned out to be the sound parameters that have significant impact on improving the satisfaction of vehicle door opening sound. Moreover, the affective adjectives 'Unstable', 'Quiet', and 'Clear' were confirmed to be the affective variables that influence the auditory satisfaction in the door opening quality. Through statistical analysis on the satisfaction of the opening sounds, we expect that a satisfaction model of vehicle door opening sounds can be developed based on the auditory parameters and the affective adjectives of vehicle door opening quality — to further aid designing procedure of vehicle door opening quality for improving affective satisfaction.
\end{abstract}

Keywords: Affective engineering, Affective sound quality, Vehicle door, Door opening sound, User satisfaction model

\section{Introduction}

There have been many efforts to improve user satisfaction for the driver in the area of affective engineering. The gap between vehicles' quality in performance and function has been reduced. Also, because driving has become important in daily life, consumers pay more attention on affective quality. Therefore, considering consumer's affect in vehicle design is an important factor for product development and sales $[1,2]$.

Consumers place value on both vehicle's functions and design factors which satisfy their affective needs [3]. Thus, the affective engineering, which translate consumer's affection and needs on functions and designs of product into the domain of product design, have to be implemented in product development process [4].
There are a growing number of researches about the influence of vehicle sounds $[5,6,7]$ on human affection using sound parameters. In the early days, they were mostly about engine sounds among the noises. Gonzalez et al. [8] developed Active Noise Control (ANC) to control the engine sound and investigated its effectiveness using psychoacoustic parameters. Also, Coen et al. [9] determined which sound quality parameters affect comfortability of users from engine sound using Automatic Relevance Determination (ARD) and rated the parameter ranking based on its effectiveness.

There are also studies about other various parts of vehicle sound. Parizet et al. [10] divided door closing sounds of vehicles into groups with representative sounds of each group based on subjective similarity and investigated the relationship between the representative sounds and perceived quality, and subjective affection. Nykänen and Sirkka [11] defined perceptually 
prominent attributes of Power Window sound and suggested a guideline to maximize subjective overall product quality using acoustic metrics. Also, Leite et al. [12] developed a model to predict subjective response of users to Heating, Ventilation, Air conditioning (HVAC) system sounds using significant attributes of sound parameters.

However, these researches are not sufficient to identify the relationship between satisfaction of drivers or passengers and sound from moving parts of vehicle (e.g., front door, rear door, trunk, etc.). Especially, there has been a lack of studies investigating the relationship between the satisfaction and door sound of vehicle.

In addition, the affective engineering research of door sound was focused to develop a model of user satisfaction based on affective adjectives perceived from door closing sound $[10,13]$. There is no research about developing an affective model that considers sound parameters and satisfaction of door opening sound.

The study aims to investigate the relation between the satisfaction and door opening sound of vehicle. An affective model was developed through assessments of affective variables which influence the satisfaction. In addition, sound parameters which affect the satisfaction of users were identified to suggest a design guideline for maximizing the satisfaction.

\section{Method}

\subsection{Affective variables in door opening sound}

For the research, at first, 15 adjectives were selected through literature surveys and expert reviews for subjective evaluation. Pilot test was conducted based on the selected adjectives to prescreen and choose suitable affective variables. Finally, Choose the 7 affective variables was followed; 'unstable', 'quiet', 'tight', 'sharp', 'rough', 'heavy', and 'satisfaction' (Table 1).

Table 1. Selected affective variables of vehicle door opening sound

\begin{tabular}{l|c}
\hline $\begin{array}{c}\text { Affective } \\
\text { variable }\end{array}$ & Description \\
\hline Unstable & Not stable; likely to change or come to an end \\
\hline
\end{tabular}

\begin{tabular}{l|l}
\hline & suddenly \\
\hline Quiet & Making or characterized by little or no noise \\
\hline Clear & Not hoarse; distinctly perceptible to the ear \\
\hline Sharp & $\begin{array}{l}\text { Having or emitting a high-pitched and sharp } \\
\text { tone or tones }\end{array}$ \\
\hline Rough & $\begin{array}{l}\text { Not sounding soft or gentle, and often } \\
\text { rather unpleasant or angry }\end{array}$ \\
\hline Heavy & Full and loud and deep; heavy sound \\
\hline Satisfaction & Giving or affording satisfaction \\
\hline
\end{tabular}

\subsection{Sound parameters in door opening sound}

Ten sound parameters were selected based on existing research findings. Then, five significant design parameters were chosen through expert evaluations and pilot tests on seven vehicles; the removed five parameter-values showed no difference among the sample vehicles (Table 2).

Table 2. Selected sound parameters of vehicle door opening sound

\begin{tabular}{c|l|c}
\hline $\begin{array}{c}\text { Sound } \\
\text { parameter }\end{array}$ & \multicolumn{1}{c}{ Definition } & $\begin{array}{c}\text { Ref } \\
\text { eren } \\
\text { ce }\end{array}$ \\
\hline Loudness & $\begin{array}{l}\text { Attribute of auditory sensation in terms of } \\
\text { which sounds can be ordered on a scale } \\
\text { extending from quiet to loud }\end{array}$ & {$[14]$} \\
\hline Sharpness & $\begin{array}{l}\text { Among other things, can be regarded as a } \\
\text { measure of tone color }\end{array}$ & {$[15]$} \\
\hline Roughness & $\begin{array}{l}\text { Governed by temporal variations of a sound } \\
\text { and reaches a maximum for modulation } \\
\text { frequencies around 70 Hz }\end{array}$ & {$[16]$} \\
\hline $\begin{array}{l}\text { Long-term } \\
\text { loudness }\end{array}$ & $\begin{array}{l}\text { Method for combining a series of individual } \\
\text { (per-frame) level estimates, obtained using } \\
\text { any of a variety of method }\end{array}$ & {$[14]$} \\
\hline loudness & $\begin{array}{l}\text { Derived by smoothing the instantaneous } \\
\text { loudness with respect to time using various } \\
\text { psycho-acoustically motivated time } \\
\text { constants }\end{array}$ & {$[17]$} \\
\hline
\end{tabular}

\subsection{Evaluation questionnaire for door opening sound}

A survey to evaluate the subjective response on the opening sounds was composed of three sections; questions about personal information, explanation about experiment methods and steps, and questions for subjective evaluation 
on each sound. The personal information questions consisted of gender, age, driving experience, and type of owned car. The experiment was explained to subjects with an instruction of each step and methods. Lastly, the subjective evaluation was assessed on 7-point Likert scale for the affective variables and on 100-point scale for the satisfaction.

\subsection{Selected vehicle door opening sound in evaluation}

In this study, the experiment was conducted for door opening sounds of vehicles. The vehicles in the experiment were composed of 26 sedans and the opening sounds were recorded in anechoic room of Hyundai NGV research center to minimize the effect of noise (Figure 1).

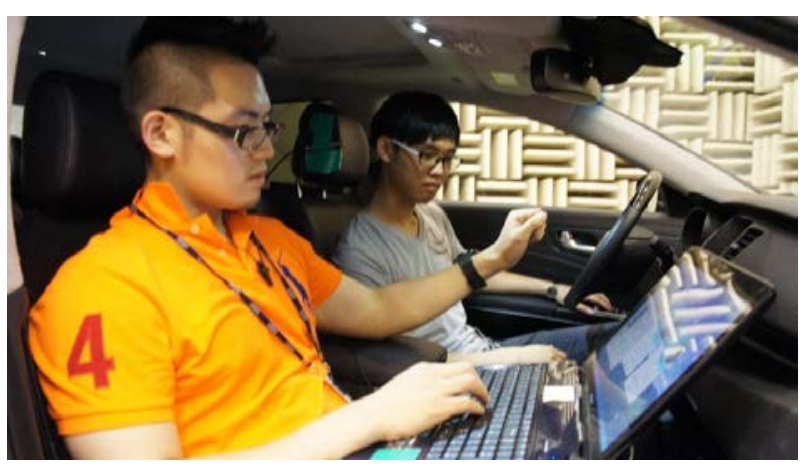

Figure 1. Recording sound in anechoic chamber in Hyundai-NGV research center

\subsection{Research procedure and participants}

Total 30 subjects (male: 17, female: 13) were recruited in this experiment. Before begin the test, the instructions and explanations were given to the subjects. To avoid bias and distortion of data, recorded samples were randomly organized for each subject. The subjects listened to the each sample five times and evaluated the affective questions. YAMAHA-MSP7 speaker was used for subjects to listen the sounds. 52A of TES Company, which is measuring device of sound level meter, was used for the same decibel test-environment to provide equivalent sound volume to the subjects (Figure 2).
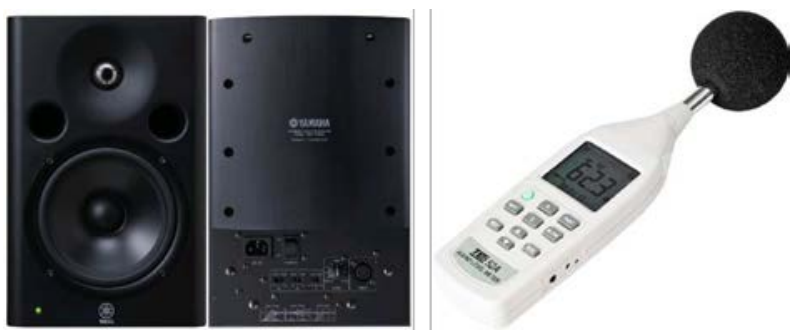

Figure 2. Speaker using experiment (left), measurement equipment of SPL (right)

\section{Results}

\subsection{Analysis of relationship between 'Satisfaction' and demographic characteristics}

The relationship between demographic characteristics of subjects and user satisfaction of door opening sounds was analyzed by using ANOVA. There were significant differences between the satisfaction and each characteristic gender, age and years of driving (Table 3). Tukey's HSD test was applied for post-hoc analysis based on ANOVA results to identify difference of satisfaction among the characteristics (Figure 3). The results show that significant difference was found between 30's and the other groups. In case of driving year, there were significant differences between $5 \sim 10$ years and the others. And in case of automobile ownership, there were significant differences between domestic middle and domestic full.

Table 3. Summary of ANOVA for demographic variables $(a=0.05)$

\begin{tabular}{l|c|c|c}
\hline \multicolumn{1}{c|}{ Independent variable } & df & $\mathrm{F}$ & $\mathrm{P}$ \\
\hline Gender & 1 & 6.444 & .011 \\
\hline Age & 3 & 9.563 & .000 \\
\hline Driving Year & 2 & 15.602 & .000 \\
\hline Automobile Ownership & 3 & 13.287 & .000 \\
\hline
\end{tabular}



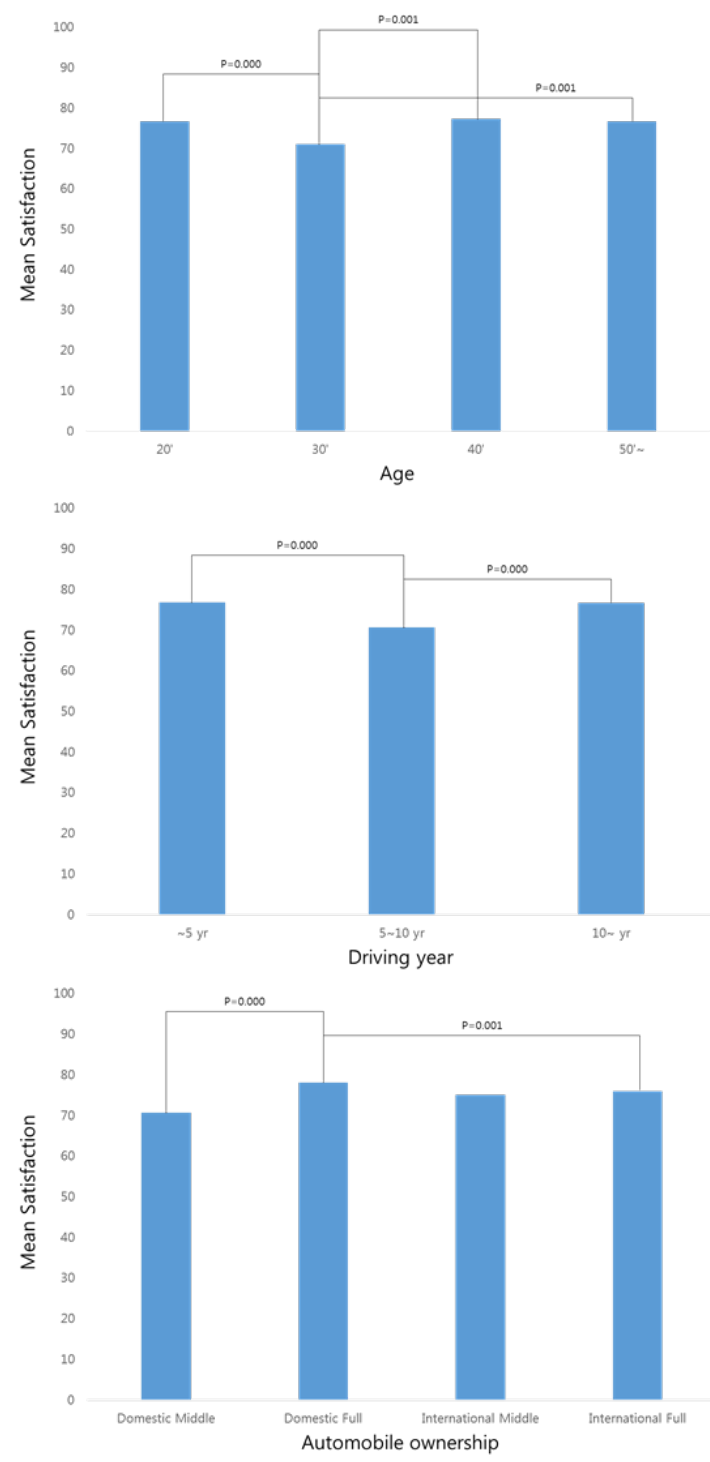

Figure 3. Summary of post-hoc ANOVA for age, driving year $(a=0.05)$

\subsection{Regression analysis of relationship between 'Satisfaction' and affective variables}

Regression analysis was applied to identify the relationship between satisfaction and other affective features. The results shows that satisfaction is negatively affected by 'unstable' and 'rough' variables, and is positively related to 'quiet', 'tight', 'sharp', and 'heavy'. The relationship between satisfaction and affective variables which influence the satisfaction are derived by the regression analysis as below Eq. (1)

$$
y=-3.12 \times \text { unstable }+2.08 \times \text { queit }+4.16 \times \text { clear }+2.17
$$$$
\times \text { sharp }-1.16 \times \text { rough }+2.08 \times \text { heavy }+46.14
$$

In the variables, the significant variables in $90 \%$ of confidence interval are 'unstable', 'tight', 'sharp', and 'heavy'. Especially, 'tight' and 'unstable' are found as the most important affective variables for consisting of the user satisfaction of door open sound (Table 4).

Table 4. The result of regression analysis between satisfaction and affective variables $(F(6,17)=58.678$,

$$
\left.\mathrm{p}=0.000, \mathrm{R}^{2}=.954\right)
$$

\begin{tabular}{|c|c|c|c|c|c|}
\hline \multirow[b]{2}{*}{ Model } & \multicolumn{2}{|c|}{ unstandardized } & \multirow{2}{*}{$\begin{array}{c}\text { standardize } \\
\text { beta }\end{array}$} & \multirow[b]{2}{*}{$\mathrm{t}$} & \multirow[b]{2}{*}{ Sig. } \\
\hline & B & $\begin{array}{l}\text { Std. } \\
\text { Error }\end{array}$ & & & \\
\hline (Constant) & 46.135 & 15.552 & & 2.966 & .009 \\
\hline unstable & -3.116 & 1.596 & -.405 & -1.953 & .067 \\
\hline quiet & 2.077 & 1.401 & .351 & 1.483 & .156 \\
\hline tight & 4.159 & 1.686 & .363 & 2.466 & .025 \\
\hline sharp & 2.165 & 1.130 & .205 & 1.917 & .072 \\
\hline rough & -1.159 & 2.222 & -.163 & -.521 & .609 \\
\hline heavy & 2.080 & .993 & .206 & 2.094 & .052 \\
\hline
\end{tabular}

\subsection{Analysis of relationship between affective variables and sound parameters}

In order to identify which sound parameters affect the satisfaction of door opening sound, regression analysis was applied, and Eq. (2) was derived. In the result, Variance Inflation Factor (VIF) was greater than 10 among loudness, short-term loudness, and long-term loudness. Thus, short-term loudness, which has highest $\mathrm{R}^{2}$ value in the regression model, was only selected to the model, and the other two parameters were removed.

In the variables, 'SharpnessZ' has been positive effect in satisfaction, and 'Short-term loudness', 'Roughness' has been negative effect in satisfaction

$$
\begin{array}{r}
\mathrm{y}=3.16 \times \text { SharpnessZ-2.01 } \times \text { Short-term } \\
\text { Loudness-7.50 } \times \text { Roughness }+81.27
\end{array}
$$


Table 5. The result of regression analysis between satisfaction and sound parameters $(F(3,16)=7.453$,

$$
\left.\mathrm{p}=0.002, \mathrm{R}^{2}=.583\right)
$$

\begin{tabular}{|c|c|c|c|c|c|}
\hline \multirow[b]{2}{*}{ Model } & \multicolumn{2}{|c|}{ unstandardized } & \multirow{2}{*}{$\begin{array}{c}\text { standardize } \\
\text { beta }\end{array}$} & \multirow[b]{2}{*}{$\mathrm{t}$} & \multirow[b]{2}{*}{ Sig. } \\
\hline & B & $\begin{array}{l}\text { Std. } \\
\text { Error }\end{array}$ & & & \\
\hline (Constant) & 81.269 & 6.443 & & 12.614 & .000 \\
\hline SharpnessZ & 3.160 & 3.263 & .166 & .969 & .345 \\
\hline $\begin{array}{l}\text { Short-term } \\
\text { Loudness }\end{array}$ & -2.008 & .783 & -.906 & -2.564 & .019 \\
\hline Roughness & -7.495 & 4.433 & .165 & -1.691 & .107 \\
\hline
\end{tabular}

\section{Conclusion}

This study aimed to develop an affective model of user satisfaction by investigating the satisfaction of door opening sound. Through literature study and expert reviews, seven affective adjectives and three sound parameters, which affect satisfaction of user when listening to door opening sounds, were selected. The experiment was conducted to 30 subjects, and an affective model was developed by investigating satisfaction, the affective variables, and the sound parameters. The model explains the relationship between satisfaction of door opening sounds and the affective variables, and sound parameters.

At first, there is significant difference between satisfaction of door opening sounds and each demographic characteristic. For this reason, these demographic characteristics have to be considered to design the vehicle door sound.

The affections that consist of satisfaction of the door opening sound are figured out; 'unstable', 'quiet', 'tight', 'sharp', 'rough', and 'heavy'. The affections 'unstable' and 'sharp' are identified as the most important affections. Further, short-term loudness is the most influential sound parameters among the threes from the regression model which maximize the satisfaction of door opening sounds.

In this study, significant affections influencing user satisfaction of door opening sound are identified. Also, a compelling model of sound parameters is derived to maximize the significant affections of users. Hence, this study is expected to help designers to optimize door opening sounds which satisfy affection of users.

\section{Acknowledgements}

This work was funded by grants from Hyundai-NGV.

\section{References}

[1] Norman, D. A., Emotional design: Why we love (or hate) everyday things. Basic books, 2004.

[2] Khalid, H. M., \& Helander, M. G, Customer emotional needs in product design. Concurrent Engineering, 14(3), 197-206, 2006.

[3] Helander, M. G, Khalid, H. M., Lim, T. Y., Peng, H., \& Yang, X., Emotional needs of car buyers and emotional intent of car designers. Theoretical Issues in Ergonomics Science, 14(5), 455-474, 2013.

[4] Nagamachi, M., Kansei engineering as a powerful consumer-oriented technology for product development. Applied ergonomics, 33(3), 289-294, 2002.

[5] Patsouras, C., Fastl, H., Patsouras, D., \& Pfaffelhuber, K., Psychoacoustic sensation magnitudes and sound quality ratings of upper middle class cars' idling noise. Proc. 17. ICA Rome, 2001.

[6] Lee, H. H., \& Lee, S. K., Objective evaluation of interior noise booming in a passenger car based on sound metrics and artificial neural networks. Applied ergonomics, 40(5), 860-869, 2009.

[7] Li, F., \& Zuo, Y., Psychoacoustic Evaluation Model on the Luxury of Sound Quality in Vehicle Interior Noise. Research Journal of Applied Sciences, Engineering and Technology 5(22): 5325-5329, 2013.

[8] Gonzalez, A., Ferrer, M., De Diego, M., Pinero, G., \& Garcia-Bonito, J. J., Sound quality of low-frequency and car engine noises after active noise control. Journal of Sound and Vibration, 265(3), 663-679, 2003.

[9] Coen, T., Jans, N., Van de Ponseele, P., Goethals, I., De Baerdemaeker, J., \& De Moor, B., Engine sound comfortability: relevant sound quality parameters and classification. In Proceeding of IFAC (p. 6), 2005.

[10] Parizet, E., Guyader, E., \& Nosulenko, V., Analysis of car door closing sound quality. Applied Acoustics, 69(1), 12-22, 2008.

[11] Nykänen, A., \& Sirkka, A., Specification of component sound quality applied to automobile power windows. Applied Acoustics, 70(6), 813-820, 2009.

[12] Leite, R. P., Paul, S., \& Gerges, S. N., A sound quality-based investigation of the HVAC system noise of an automobile model. Applied Acoustics, 70(4), 636-645, 2009.

[13] Kuwano, S., Fastl, H., Namba, S., Nakamura, S., \& Uchida, H., Quality of door sounds of passenger cars. Acoustical science and technology, 27(5), 309, 2006.

[14] Fastl, H., \& Zwicker, E., Psychoacoustics: Facts and models (Vol. 22). Springer Science \& Business Media, 2007.

[15] von Bismarck, G., Sharpness as an attribute of the timbre of steady sounds. Acta Acustica united with Acustica, 30(3), 159-172, 1974.

[16] Terhardt, E., Über akustische rauhigkeit und schwankungsstärke. Acustica, 20(215-224), 37-38, 1968. 
[17] Glasberg, B. R., \& Moore, B. C., A model of loudness applicable to time-varying sounds. Journal of the Audio Engineering Society, 50(5),

331-342, 2002 .

\section{Author listings}

Wonjoon Kim: wjkim0114@gmail.com

Highest degree: M.S, Department of Industrial Engineering, Seoul

National University

Position title: Ph.D candidate, Department of Industrial Engineering,

Seoul National University

Areas of interest: Human Factors in vehicle environment, HCI

Taebeum Ryu: tbryu75@me.com

Highest degree: Ph.D, Division of Mechanical and Industrial Engineering, Pohang University of Science and Technology

Position title: Professor, Department of Industrial and Management

Engineering, Hanbat National University

Areas of interest: Affective Engineering, User Interface

Yu Shin Lee: keynote1112@gmail.com

Highest degree: B.S., Department of Mechanical Engineering, KAIST, Position title: Ph.D Candidate, Department of Industrial Engineering, Seoul National University

Areas of interest: Biomechanics, $\mathrm{HCI}$

Donggun Park: donggun.park@snu.ac.kr

Highest degree: B.S., Department of Industrial Engineering, Purdue University

Position title: Ph.D Candidate, Department of Industrial Engineering,

Seoul National University

Areas of interest: Human Factors, User Interface

Myung Hwan Yun: mhy@snu.ac.kr

Highest degree: Ph.D, Department of Industrial and Manufacturing Engineering, Penn State University

Position title: Professor, Department of Industrial Engineering, Seoul

National University

Areas of interest: Biomechanics, Product Design and Development, HCI,

Affective engineering 